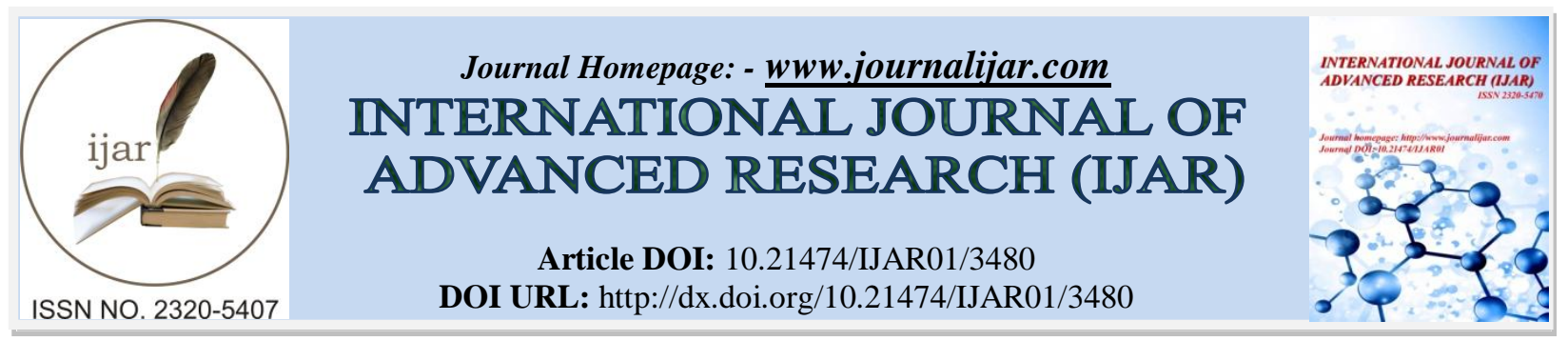

RESEARCH ARTICLE

\title{
INTRAORAL PHOTOGRAPHY IN ORAL MEDICINE -THE USE OF SMARTPHONE CAMERA.
}

\author{
Dr. Lakshmi. C and Dr. G. Maragathavalli
}

A study of Recent Advances in Technology.

\section{Manuscript Info}

Manuscript History

Received: 07 January 2017 Final

Accepted: 05 February 2017

Published: March 2017

\begin{abstract}
The aim of this study was to report the use of smartphone cameras for intraoral photography in oral medicine. The smart phone photographs were evaluated to determine if they would be useful for diagnosis and other applications in oral medicine. In the absence of a standard intraoral camera system, it was found that smart phones could be useful in capturing and transmitting digital intraoral images that could assist in dental education, tele dentistry and other aspects.
\end{abstract}

Copy Right, IJAR, 2017,. All rights reserved.

\section{Introduction:-}

Due to the technological revolution, the use of smart phone cameras substitutes in the absence of an intra oral camera or DSLR camera set up.

Smart phones are high end mobile phones with advanced computing ability and connectivity. Current models combine many functions and can be accessed via the internet. Smart phones have been sporadically mentioned in literature. The mobility, communication functions, relative to supporting treatment at distant locations, a process known as telemedicine.

The primary purpose of this study was to evaluate the feasibility of dental students acquiring and transmitting intraoral images to the dental specialist using a smart phone technology.

\section{Material \& Methods:-}

The study was conducted in the Department of Oral Medicine \& Radiology of our esteemed institute. A smart phone with the following specifications were used.

\begin{tabular}{|l|l|}
\hline Primary & $16 \mathrm{MP}, \mathrm{f} / 2.2,31 \mathrm{~mm}$, OIS, autofocus, LED flash, check quality \\
\hline Features & $\begin{array}{l}1 / 2.6 " \text { sensor size, } 1.12 \mu \mathrm{m} \text { pixel size, geo-tagging, touch focus, face/smile detection, } \\
\text { panorama, HDR }\end{array}$ \\
\hline Video & 2160p@30fps, 1080p@60fps, dual-video rec., check quality \\
\hline
\end{tabular}

Intraoral photographs with no extra oral imaging were acquired from 4 different patients with four different lesions. Informed consent was obtained and patient's basic information recorded on a proforma. The smartphones were used by the postgraduate students. The brand of the smartphone would be kept hidden and will not be compared to another brand. The students were asked to take photographs in different angles and numbers.

All intra-oral photographs were acquired with the smartphone cameras in a horizontal direction. Metal retractors and intraoral mirrors were used. No external light sources were used. The LED auto lighting of the camera flash was used. 
None of the images were enhanced or edited prior to transfer onto the computer system and were viewed by photography experts.
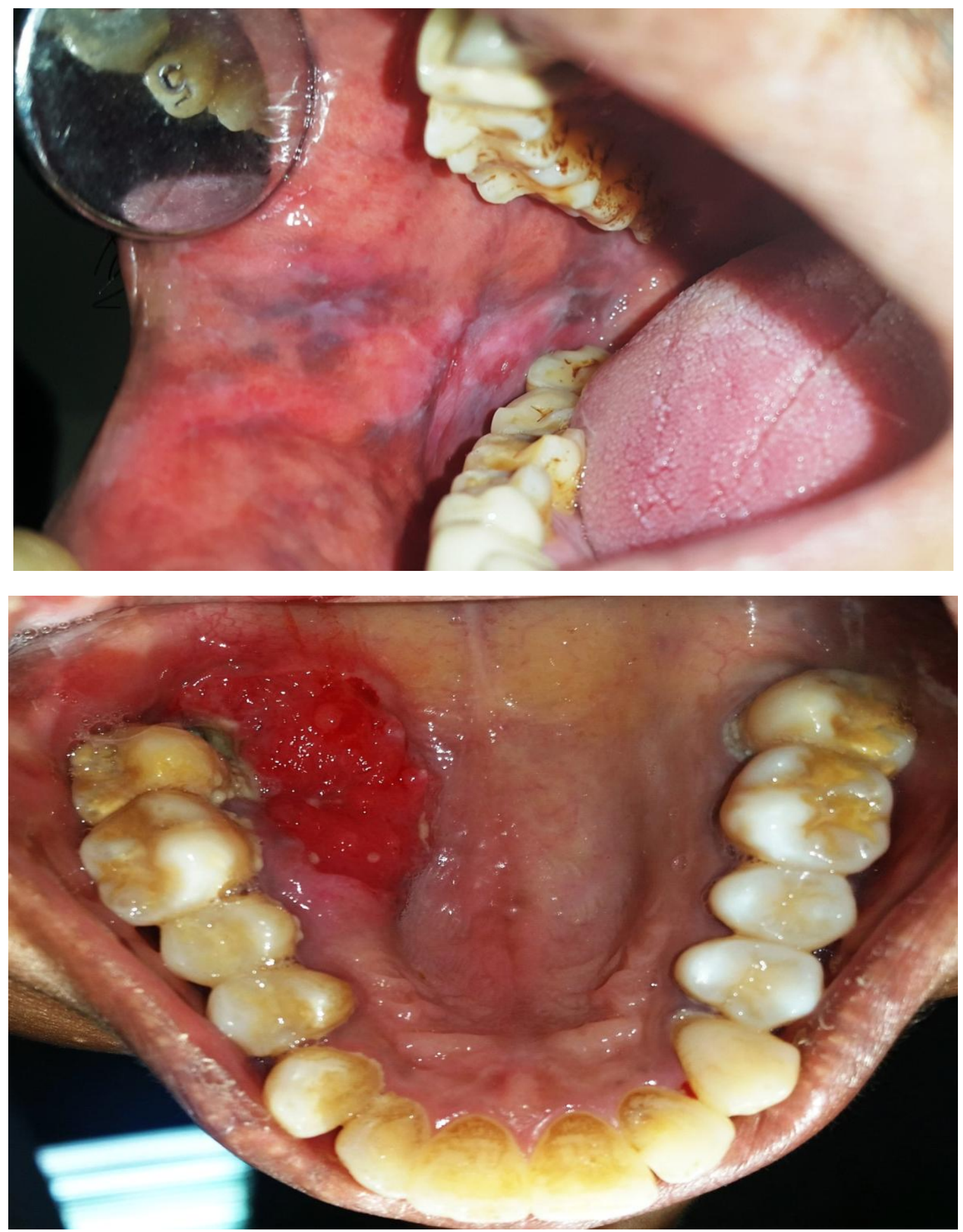

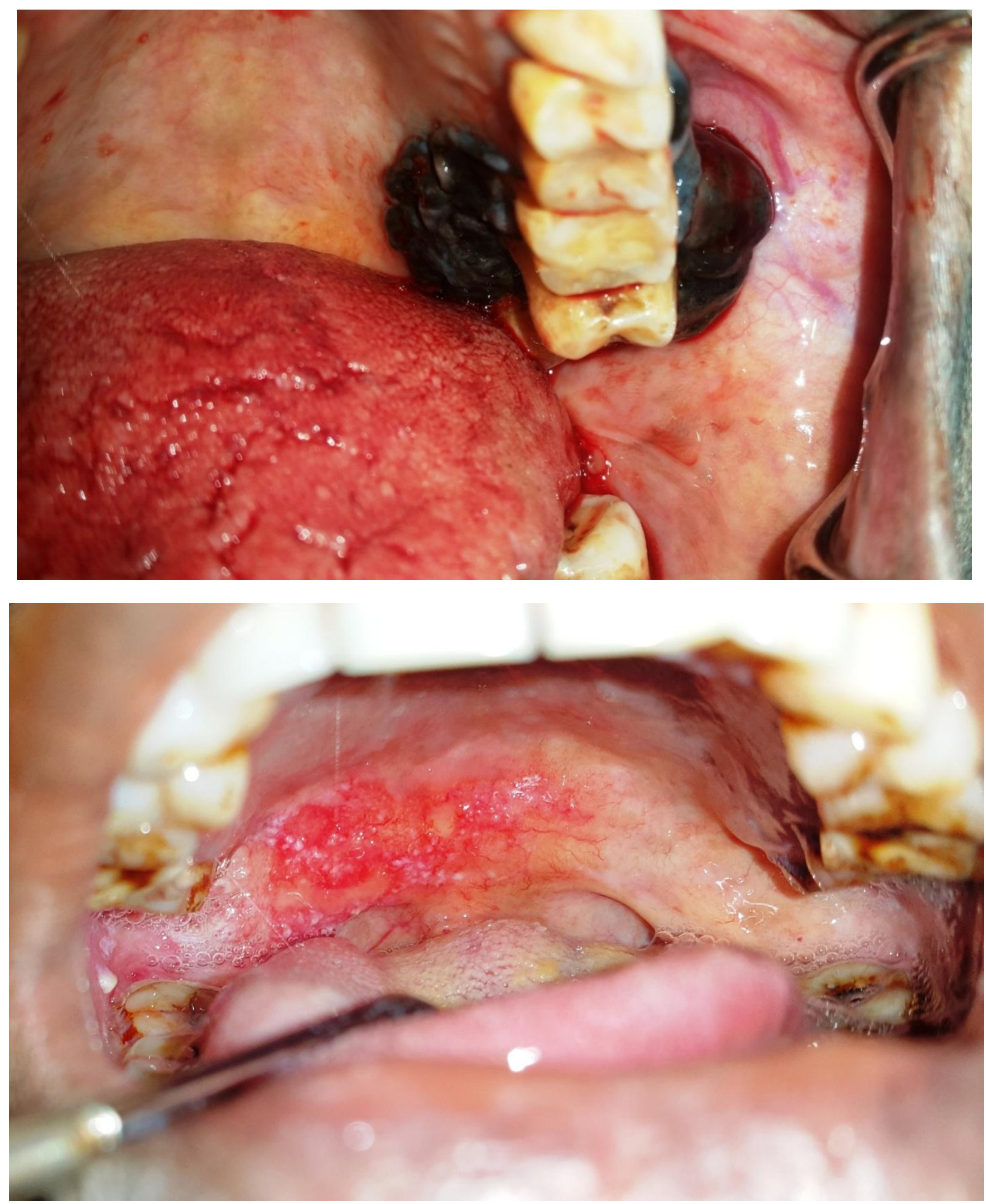

\section{Results:-}

The assessment of the photographs were done by the oral medicine specialist and a photography expert. They agreed that, given the characteristics of the intra oral photographs produced by the smart phone, they could use those photographs to assist in diagnosis, treatment planning. 
According to the speciality of Oral Medicine, when coupled with the signs and symptoms, smart phone photographs: Could lead to a rank ordered clinical differential diagnosis provided to the practitioner via text messaging or email, with treatment recommendation. This would be beneficial for solo practioners in locations without access to servers. Could assist in biopsy material submission. Intra operative surgical photos may provide valuable information regarding consistency and form of the lesions.

\section{Discussion:-}

The photographs could be taken without a hindrance with the use of metal cheek retractors and intraoral mirror. Tongue retraction however was difficult. If the smart phone device was held steadily, there were very low incidence of blurring of images.

Using smart phone cameras for intraoral photography is not seen as an alternate to the need of using specialized intraoral photographic equipment. As in all, the minimum requirements for the smart phone images to be useful include -

Proper focus on the intended area.

Sufficient lighting.

Consistency of colour of images.

Surprisingly, very few problems or no problems were faced with light source as the LED light being close to the lens in the smart phones.

The smart phones are compact to handle and due to pre specified settings, photographs could be taken more quickly. Intraoral video recording also was done successfully.

\section{Conclusion:-}

This project demonstrates that intraoral photographs can be efficiently taken using smart phone cameras and the images relatively quickly transferred or shared among inter disciplinary professionals for quick viewing, patient education and to store inter visit records,

\section{References:-}

1. P Loiacono and L Pascoletti. Photography in Dentistry. Theory and Techniques in Modern Documentation. Rho (MI), Quintessenza Edizioni S.r.l., Italy, 2012.

2. R Espejo. Smartphones. Greenhaven Press, Farmington Hills, Michigan, 2013.

3. T Wirtz. Remote Access to Patient Information for After-Hours Emergencies. Journal of Dental Education, 72 (2008), 253.

4. M McAndrew and A Johnston. The Role of Social Media in Dental Education. Journal of Dental Education, 76 (2012), 1474-1481.

5. S Aziz and V Ziccardi. Telemedicine using smartphones for oral and maxillofacial surgery consultation, communication, and treatment planning. Journal of Oral and Maxillofacial Surgery, 67 (2009), 2505-2509. 41

6. L Celi, L Sarmenta, J Rotberg, A Marcelo, and G Clifford. Mobile care (Moca) for Remote Diagnosis and Screening. Journal of Health Informatics in Developing Countries, 3:1 (2009), 17-21.

7. M Ganesan, S Prashant, V Mary, N Janakiraman, A Jhunjhunwala, and N Waidyanatha. The use of mobile phone as a tool for capturing patient data in southern rural Tamil Nadu, India. Journal of Health Informatics in Developing Countries, 5:2 (2011), 219-227.

8. B Mihailovic, M Miladinovic, and B Vujicic. Telemedicine in Dentistry (Teledentistry), Advances in Telemedicine: Applications in Various Medical Disciplines and Geographical Regions, Prof. Georgi Graschew (Ed.), (2011) InTech on line. Access provided by Google: http:www.intechopen.com/download/get/type/pdfs/id/14328. Last accessed: 10 January 2014.

9. M Rocca, V Kudryk, J Pajak, and T Morris. The evolution of a teledentistry system within the Department of Defense. Proc AMIA Symp (1999), 921-924.

10. D Herrera. Journal of Clinical Periodontology 27 (2000a), 377-386.

11. M Vyas. Clinical Photography in Dentistry. Jaypee Brothers Medical Publishers, Ltd., New Delhi, India, 2008.

12. W Bengel. Mastering Dental Photography. Quintessence Publishing Co, Ltd., New Malden, Surrey, United Kingdom, 2006. 